\title{
Computer-Assisted Concept Analysis of Customer Centricity: A Review of the Literature on Employee Engagement, Culture, Leadership, and Identity Co-Creation
}

\author{
Elanor Colleoni ${ }^{1, *}$, Flavia Bonaiuto ${ }^{2}$, Laura Illia ${ }^{3}$ and Marino Bonaiuto ${ }^{4}(\mathbb{D}$ \\ 1 Department of Business, Law, Economics, and Consumption, IULM University, 20143 Milan, Italy \\ 2 Faculty of Economics, Universitas Mercatorum, 00186 Rome, Italy; flavia.bonaiuto@unimercatorum.it \\ 3 Department of Communication and Media Research, Faculty of Management, Economics and Social Science, \\ University of Fribourg, 1700 Fribourg, Switzerland; laura.illia@unifr.ch \\ 4 Department of Psychology of Developmental and Socialization Processes, Faculty of Medicine and \\ Psychology, Sapienza University of Rome, 00185 Rome, Italy; marino.bonaiuto@uniroma1.it \\ * Correspondence: Elanor.colleoni@iulm.it
}

check for

updates

Citation: Colleoni, E.; Bonaiuto, F.; Illia, L.; Bonaiuto, M. ComputerAssisted Concept Analysis of

Customer Centricity: A Review of the Literature on Employee Engagement, Culture, Leadership, and Identity Co-Creation. Sustainability 2021, 13, 5157. https://doi.org/10.3390/ su13095157

Academic Editor: Claudia Stoian

Received: 27 March 2021

Accepted: 30 April 2021

Published: 5 May 2021

Publisher's Note: MDPI stays neutral with regard to jurisdictional claims in published maps and institutional affiliations.

Copyright: (C) 2021 by the authors. Licensee MDPI, Basel, Switzerland. This article is an open access article distributed under the terms and conditions of the Creative Commons Attribution (CC BY) license (https:// creativecommons.org/licenses/by/ $4.0 /)$.
Abstract: Customer centricity requires having customers at the core of the corporate organizational process. Yet, relationship marketing scholarships have not developed a clear understanding of how corporate culture, leadership, and identity may allow the establishment of customer centricity within the organization. To this aim, we have developed a computer-assisted concept analysis of the term customer centricity in two disciplines that are at the core of relationship marketing: business and psychology. Specifically, we have conducted our review of a sample of abstracts in the over 1200 peerreviewed journals of Business Source Premier Database and 2500 publications at the Psychology Info database that use the term "customer centricity" together with the terms "organizational identity", "organizational leadership", "organizational culture", and "employee engagement". Our computerassisted analysis allowed us to identify four main open debates scholars and practitioners are working on that contribute to advance literature on relationship marketing: employee training and balanced centricity; industries that are either best or worst practices; reinvention of marketing practices; social aspects of consumer centricity. These areas are presented considering how they might inspire future studies on customer centricity in the customer relationship marketing field.

Keywords: customer centricity; relationship marketing; organizational culture; employee engagement; organizational identity; leadership; topic modeling; computer-assisted analysis

\section{Introduction}

Building and maintaining meaningful relationships with customers has become a corporate imperative [1]. The intensified market competition along with increasingly demanding consumers have forced companies to adjust their strategies, focusing more and more on customer attraction and retention. This has sparked a renewed attention to Customer Relationship Management [2,3], the discipline which focuses on the conditions that allow companies to build customer loyalty and trust. Central to Customer Relationship Management is the concept of customer centricity [1], which refers to the idea of putting customers at the center of an organization's processes [4]. It requires looking ahead, anticipating who will be the best customers, and discovering how to do things for these selected clients so that they recognize that the company has their best interest in mind. The concept of customer centricity is usually used as opposed to that of product centricity [5,6]. "While product centricity sees the company as a set of resources and competences developing around the products or services, customer centricity focuses its attention on the customer and on the establishment of mutually satisfactory customer relationships in order to boost customer retention and loyalty" [5]. Even though there is widespread agreement in the literature that a customer centric approach is achieved when 
customer retention is the highest priority across all departments of an organization [7] it is not clear how companies can internally adopt a holistic view toward customers [7-9]. We may be at this stage because there is a lack of clarity in articulating the concept of customer centricity $[10,11]$, which hinders scholars to develop a common ground about how customer centricity can be achieved from an organizational viewpoint such as for example with strong leadership, strong organizational culture, organizational identity, employee engagement. In particular, the focus so far has been to understand better the customer, what influences loyalty from the customer's perspective. Accordingly, scholars have developed an "outside-in" perspective to customer centricity, focusing on customer related variables such as customer satisfaction, customer brand perception in relation to customer loyalty. Little research has developed an "inside-out" perspective on the concept of consumer centricity, focusing on how the company can comprehensively be internally prepared to holistically embrace a customer centricity orientation [8]. As shown by the seminal work of Hatch and Schultz [12], four corporate pillars must be aligning for a company to ensure such a customer-centric orientation: identity, culture, leadership, and employees' engagement. These have been considered central elements that allow for building internal strengths, whereby the organization is able to align any corporate action with corporate purpose and strategy. A review of how these four pillars have been investigated in the context of customer centricity would allow for understanding which strengths can be built within the organization to assure an organizational alignment toward customer centricity.

To shed some light on the main topics and open points concerning these pillars in the customer-centricity literature, we develop a review of previous studies analyzing the role of organizational identity, culture, employee engagement, and leadership for customer centricity. Such review aims to set the basis to understand what issues scholars commonly consider when discussing customer centricity from an "inside-out" perspective. We provide this overview by developing a focus on the language used by scholars in their scholarly manuscripts and practitioners in their journal articles. Our approach is comparable to that of previous studies [13-17] that have reviewed the content of scholars' works on the topic. Taking inspiration from them, our idea here is to draw a picture of the common (or diverse) direction that both business and psychology scholars are taking regarding the topic under review. Specifically, we seek to find an answer to the following question: What common themes do scholars develop when discussing customer centricity in the areas of organizational identity, organizational culture, organizational, leadership, and employee engagement? The intention is to illustrate common themes debated as well as revealing issues commonly discussed across scholars and fields.

\section{Customer Relationship Marketing and Customer Centricity}

Since its introduction in service marketing and business-to-business marketing thirty years ago [18,19], relationship marketing has become one of the central concepts in marketing [3]. Relationship marketing has changed the focus from attracting customers to satisfying and maintaining them [20]. As stressed by Shah et al. [6], the increasing focus on customer relationships has been driven by several factors, mainly market, societal and technological factors. The most relevant being the intensification of marketplace competition [21] which has drastically reduced the advantages derived by a competition based on mass-market strategies while increasing the relevance of preserving and nurturing the relationship with the customers [22]. Other market-related factors are the intensifying pressures to improve marketing productivity, and the increasing market diversity [6]. At the societal level, the increased educational level of the consumers along with the development of an affluent society and the consumer desire to feel unique, have caused the emergence of a more demanding and well-informed consumer. Finally, the diffusion of peer-to-peer communication technologies has allowed customer-to-customer interactions through social media and their exposure to multiple touchpoints, which in turn have dramatically reduced corporate control over consumer buying behavior [23]. Because of these concurrent factors, marketing research has focused not only on the factors facilitating 
market exchange, but also on the factors crucial for maintaining relationships [3], such as relationship benefits [24], relationship value [25], trust [26], and commitment [27].

During the last twenty years, the idea that developing strong relationships with customers is a strategic source for corporate value creation has become widely accepted, suggesting a paradigm shift in marketing from a product to a customer orientation [28,29]. Accordingly, Vargo and Lusch [30] have suggested that marketing has evolved from a gooddominant logic to a service-dominant logic. Several researchers have shown the benefit of building strong and trusted relationships with the customers, presenting evidence of the relevance of customer loyalty and satisfaction in driving business performances. Heskett [31] has shown how profit and growth are stimulated primarily by customer loyalty. Reichheld [32] has shown that the benefit of enhanced customer loyalty in service firms are increased revenue, reduced customer acquisition costs, and lower costs of serving repeat. By investigating business-to-business companies, Lam et al. [33] have shown how loyal customers can offer a continuous stream of revenue for a company by remaining with the brand and rejecting the overtures of competitors. Using American Customer Satisfaction Index data, Morgan and Rego [34] found evidence that also customer satisfaction has great value in predicting future business performance. Shankar, Smith, and Rangaswamy [35] have investigated whether there are significant differences in customer loyalty and customer satisfaction in online and offline environments. They found that the relationship between overall satisfaction and loyalty is stronger online than offline and there is a positive reciprocal relationship between loyalty and satisfaction online, suggesting that contrary to popular fears, the online medium could help firms build a loyal customer base. Recently, using 15 years of audited returns, Fornell et al. [36] have shown empirical evidence that stock returns on customer satisfaction do beat the market.

In sum, all this evidence has driven the emergence of Customer relationship management (CRM), that, contrary to initial relationship marketing that concentrated mainly on building strong long-term relationships, has instead focused "on the extraction of the value hidden in these relationships by optimizing customer profitability and customer lifetime value" [37].

At the heart of Customer Relationship Management lays the concept of customer centricity [1]. As pointed out by Gee et al. [7], to put up and front of the customer, it is imperative for a company to develop a customer centric vision. Customer centricity stresses the need for businesses not only to adopt a customer-centric vision $[5,26]$ but also to recognize that customers are different and strategically target customers for whom the marketing effort will pay off [4,25].

\section{Culture, Identity, Employee Engagement and Leadership as Important Concepts to Focus on and to Develop an Inside-Out Approach to Customer Centricity}

According to Gee et al. [7], a customer centric approach is achieved when the belief that customer retention is of the highest priority transcends through all departments of an organization [7]. However, as pointed out by Hart [8], while customer centricity is an extremely attractive concept, it is sometimes difficult to build and sustain. This is mainly due to the difficulties companies face internally to adopt this holistic view $[7,9]$.

Previous studies suggest that a company willing to foster a customer-centric approach faces the following challenges. First, how to develop an organizational culture that is oriented toward customer-centricity [4]. Not only there are still discussions on the value of establishing a customer-centric organizational culture [38,39], but among those scholars who recognize its value, there is still a debate on how one can establish it [40]. Specifically, there is an ongoing open debate [4] on how organizations can install reward systems toward employees who are future and relational-oriented, rather than backward and performance-oriented. To this aim, some scholars argue that companies must focus on employee engagement [40], while according to other researchers, the focus should be on establishing a strong organizational identity [41]. Moreover, according to some scholars, the focus should be on working on strong leadership and identity $[6,42]$. 
Despite extant research suggests that identity, culture, leadership, and employee engagement are crucial to aligning the organization toward customer centricity, there is still little agreement on how customer centricity can be achieved combining these focal points, and, as a consequence, this issue remains "a chronic headache" [42]. In the next paragraph, we develop a computer-assisted concept analysis that allows for the development a systematic overview of scholarship focusing on these constructs in the context of customer centricity.

\section{Computer-Assisted Concept Analysis as a Literature Review}

By taking inspiration from previous studies $[15,17,43,44]$, we conducted a computerassisted analysis to develop an informed literature review on a concept, identifying the main semantics of debates that scholars develop in their abstracts (including article titles). We focused on the abstracts and article titles on the assumption that "abstracts and titles are relevant texts for the analysis because terms appearing in them are key in describing the article in terms of both its primary assumptions and fundamental results" [15]. As previous studies have underlined $[15,17,43,44]$, while this choice limits our ability to analyze what is written in the paper's main manuscript, this limitation has little consequences on our analysis that instead is not meant to "trace an evolution of the term, neither to identify its key authors" [17].

The advantage of this type of computer-assistant review is that it allows a wellinformed review of previous works as it starts from a systematic analysis of the core content of papers that is not filtered by the researcher. This not only reduces biases during the review process (e.g., bias due to researchers' previous knowledge on the topic), but it also allows to better identify common discussions in extant research by systematically identifying semantics $[15,17,43,44]$. It, therefore, provides an initial interesting mapping for researchers doing the review who then go to read the papers by keeping in mind that these papers share a common semantic and focus.

It is important to understand that this type of computer-assisted analysis does not imply that researchers avoid engaging with the papers' conceptual frameworks and debate. They do so as in a traditional literature review. However, they do so with the support of the outputs that are provided inductively by the computer-assisted analysis, which allows for the identification clusters of studies and to deepen into them by keeping in mind the main focus, which is so defined in an objective way.

\subsection{Selection of Abstracts}

To achieve our final aim, we collected one main dataset that was the core of our analysis. We collected those abstracts and titles naming the term "customer centricity" together with the terms "organizational culture"; "employee"; "leadership", "organizational identity", and "co-creation" within the 1200 abstracted journals from the Business Source Premier database (EBSCO publishing) and 2500 journals listed in the PsycInfo database (American Psychological Association). We chose these two databases because of their primary focus on organizational issues from either a business or psychology perspective. Though we recognize that we cannot assume that all papers appearing in the Business Source Premier or PsycInfo databases are in business and psychology, respectively, the selection of these two datasets assure have a high probability of including in our review papers that have the objective to contribute to issues related either to these two fields of study. For the purpose of the study hereafter, we refer to papers coming from these two databases respectively by scholars in management vs psychology. However, it is important to stress that this means scholars are interested in managerial vs psychology issues, rather than working in business vs psychology departments, schools, etc. We included peer-reviewed journals, conference proceedings, and periodicals published up to March 2019 in our analysis. In total, we identified 88 abstracts (after removing the duplicates). Table 1 presents the frequency of abstracts per keyword. We can see that the concept of customer centricity is mainly used within business studies with a ratio of $80 \mathrm{vs.} 8$ articles 
compared to psychology studies. Furthermore, scholars focus their attention mostly on employee engagement, co-creation, and culture, rather than on leadership. No studies focused their attention on organizational identity. The distribution of abstracts according to the year of publication indicates that among papers available in Business source premier, the term "consumer centricity" acquired particular importance in the years 2005 and 2010, after which studies started to increase regularly. However, among psychology scholars, the term gained importance during the years 2014-2016. Table A1 in Appendix A shows more in detail the list of all journals of the data selection. This list confirms the multidisciplinary character of the concept.

Table 1. Frequency of abstracts per search keywords.

\begin{tabular}{|c|c|c|c|c|c|}
\hline & “Employee" & $\begin{array}{l}\text { "Organizational } \\
\text { Culture" }\end{array}$ & "Leadership" & $\begin{array}{l}\text { "Organizational identity" } \\
\text { or "Co-Creation" }\end{array}$ & Tot \\
\hline PsycInfo & 3 & 2 & 1 & 1 & 8 \\
\hline $\begin{array}{l}\text { Business Source } \\
\text { Premier }\end{array}$ & 52 & 2 & 19 & 7 & 80 \\
\hline Tot & 55 & 4 & 20 & 8 & 88 \\
\hline
\end{tabular}

\subsection{Analysis}

We pre-coded the dataset in order to be able to retrieve how semantics significantly relate to which dataset (either Business Source Premier or PsycInfo) and to which area of reference (employee, organizational culture, leadership, or co-creation). This double tagging allowed the emerging discussions to be mapped according to disciplines and areas, to identify which ones are particularly relevant in transmitting which common discussion. We carried out a topic modeling analysis [16] with the help of the software WordStat. WordStat investigates the distribution of vocabulary in texts. A co-occurrence analysis of the text allows the identification of points of view that are shared by different sources [44] (in our case, articles with a specific focus on leadership vs. identity vs. employees vs. identity), given a particular disciplinary approach (in our case management vs. psychology) on a particular topic (in our case, customer centricity). The underlying assumption of WordStat topic extraction methodology is that different academic articles produce different ways of talking about the topic under discussion. In other words, the specific vocabulary used in the discussion is seen as a source for detecting the way scholars thinking about the topic. Topics identified represent common discussions taking place about customer centricity across scholars. Sentence and paragraph meanings are analyzed by considering local co-occurrences of words based on the probability that these words co-occur in the whole dataset of abstract/titles. The underlying idea is that the meaning of propositions and sentences can be captured if one finds the words that regularly appear together in sentences throughout the whole text.

We run the analysis with WordStat by using a basic setting and procedures, such as lemmatization and stemming, that is performed by default by Wordstat using a generalist English dictionary (given that abstracts/titles are in English). The topic modeling analysis was also run with basic settings proposed by Wordstat to avoid any bias (e.g., change the expected topics in the outcomes). A researcher willing to develop the same analysis with the same dataset will have to avoid any ad-hoc setting on the topic analysis performed by Wordsat. WordStat outputs allowed us to conduct both quantitative and qualitative analyses. Statistical methods behind the topic modeling of the software analysis are analysis for topic extraction [16], hierarchical classification based on correspondence analysis [44], and computer simulation [45]. Based on these analyses, we quantified the co-occurrences of words by both a coherence test and factorial analysis that measures the degree to which each word used in the abstract is specific for each topic. Based on this first quantitative assessment (completed by the software), we then conducted a qualitative analysis of each 
topic. We did this based on the outputs provided by Wordstat, which allows us to retrieve the text that significantly relates to a specific topic. In this way, we were able to scrutinize the original context of the discussions provided by the software via a list of words, short phrases, and statements associated with each topic.

Four main topics emerged from our analysis, as summarized in Table 2. The most prevalent topic (n. 2) relates to a debate on how to conduct employee training in order to establish customer centricity at the organization. The second biggest topic (n. 4) relates to how to reinvent marketing through customer centric service. The third topic (n. 1) pertains to articles presenting best (and worst) practices on consumer centricity. The fourth topic (n. 3) relates to the social aspects of consumer centricity.

Table 2. Topics extracted from our dataset of abstracts.

\begin{tabular}{|c|c|c|c|c|c|c|c|}
\hline Number & Topics & $\begin{array}{l}\text { Significant } \\
\text { Keywords }\end{array}$ & $\begin{array}{c}\text { Order of } \\
\text { Extraction }\end{array}$ & $\begin{array}{c}\text { Coherence } \\
\text { Index of Topic }\end{array}$ & $\begin{array}{l}\text { Frequency } \\
\text { of Words }\end{array}$ & $\begin{array}{c}\text { Cases } \\
\text { (Abstracts) }\end{array}$ & $\%$ Cases \\
\hline 2 & $\begin{array}{l}\text { Employee } \\
\text { Training and } \\
\text { Customer } \\
\text { Centricity }\end{array}$ & $\begin{array}{c}\text { Customers; Business; } \\
\text { Employees; } \\
\text { Company, Article; } \\
\text { Centricity; Customer }\end{array}$ & 2 & 0.366 & 160 & 67 & $80.72 \%$ \\
\hline 4 & $\begin{array}{c}\text { Reinventing } \\
\text { Marketing } \\
\text { Through } \\
\text { Customer } \\
\text { Centric Service }\end{array}$ & $\begin{array}{l}\text { Marketing; Service; } \\
\text { Management; } \\
\text { Services; Culture }\end{array}$ & 4 & 0.433 & 173 & 66 & $79.52 \%$ \\
\hline 1 & $\begin{array}{l}\text { Best (and worst) } \\
\text { Practices on } \\
\text { Customer } \\
\text { Centricity }\end{array}$ & $\begin{array}{c}\text { Article; Buy; } \\
\text { Company; Article } \\
\text { Focuses }\end{array}$ & 1 & 0.217 & 90 & 55 & $66.27 \%$ \\
\hline 3 & $\begin{array}{l}\text { Social Aspect of } \\
\text { Consumer } \\
\text { Centricity }\end{array}$ & $\begin{array}{c}\text { Study; Findings; } \\
\text { Creation; Research; } \\
\text { Approach; Social; } \\
\text { Dominant Logic; } \\
\text { Emerging } \\
\text { Economies; Invs }\end{array}$ & 3 & 0.557 & 143 & 36 & $43.37 \%$ \\
\hline
\end{tabular}

As the dendrogram (see Figure 1) shows, the topics that are most similar in their use of language are the topics on employee training (n. 2) and on best practices (n. 1), whereas the other two topics are standalone in the debate. This means that, to date, experts have been able to identify clear companies that represent best practices in how employee training allows customer centricity, but not on other topics identified in the analysis.

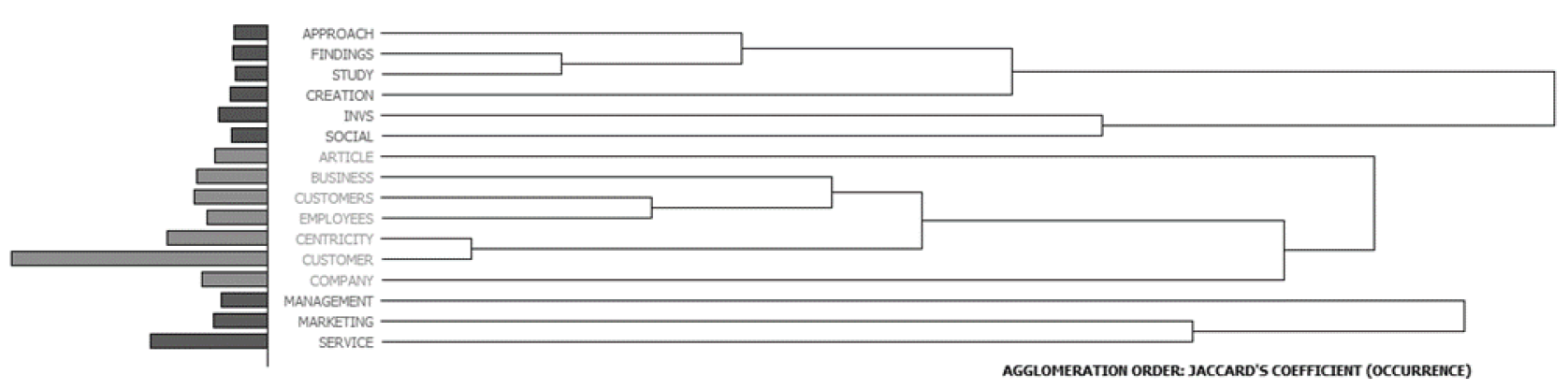

Figure 1. Dendrogram of words that are significant across topics. 


\subsection{Balanced Centricity: Employee Training for the Establishment of Customer Centricity (Topic 2)}

Studies that debate how to train employees with the aim to forge a customer centricity consider that employee centricity is necessary. The main reason is that this allows employees to better interact with the customers. We could identify two main building blocks to forge employee centricity. Both relate with how much the company is able to establish a system that allows and assesses employees' ability to establish relationships and interactions.

The first building block of employee centricity relates to the establishment of what scholars call "balanced centricity" (that is, a system of putting at the center not only the customer but all the involved agents) [10]. This implies implementing an evaluation system that focuses on the satisfaction of all agents involved, including employees and other stakeholders an employee interacts with. Basically, one has to assess the degree to which employees are satisfied with how processes allow them to establish long and good relationships with all agents (the customer being one of them). Training of employees, therefore, has to be oriented towards the improvement of interactions with all agents, rather than only with the customer.

The second building block relates to putting a system of sharing information and knowledge in the company in place, which allows employees to access data with regards to customer satisfaction surveys [46]. This empowers them to propose solutions. The basic assumption here is to allow front-line employees (rather than only managers and back-office managers) to know what customers think. This implies a change in the way some companies are managing their processes because front line employees are typically provided indications on how to behave (based on customer survey results) but are not directly confronted with the findings of these surveys (so that they can propose solutions on how to solve a customer non-satisfaction item). Hence, it is crucial to put into place a system of continuous learning, innovation, and co-sharing that starts from front-line employees, rather than top management only. The assumption is that the training proposal starts from the employee, rather than from management.

Related to this, studies in this second building block also question how to put metrics of performance in place that allow us to understand how employees-with their daily work of building relationships with customers (and other agents involved in the process with the customer)-are performing and contributing to corporate revenues. Here, it is particularly crucial to fix an assessment system that includes future-oriented performance indicators allowing the employee to understand how his/her daily work will support the company in the long run, rather than only in the short term. Only in this way can the company set up a system of rewarding employees that puts employees at the center of each long-term process, and that motivates them to contribute to it.

\subsection{Reinvention of Marketing Practices through Customer Centric Service (Topic 4)}

Studies that discuss how to reinvent marketing are opening the debate on two main areas. First, they consider that the company has to change the organizational culture toward marketing [38]. It has to change from a system that enables companies to identify customer needs in order to serve them, to a system that enables customers to identify their needs to serve themselves. Accordingly, establishing an organizational culture toward consumer centricity implies hiring marketing managers who know how to design customer services that empower the client to communicate with the company in any possible way (rather than the company to communicate with the client in any way). This allows the customer to pick the service products from the company, he/she wants at the moment he/she considers appropriate. Hence, it requires initiating a marketing management culture that considers self-service with new lenses. Rather than considering it as a mean to cut costs and fasten procedures (i.e., a system that lacks service for the customer), it is important to start considering it as a mean to empower the core customers to strengthen their relationship and augment interactions with the company (i.e., as a system that empowers the customer). 
Second, in order to reinvent marketing management, it is important that the company implements a service-dominant logic [29], rather than a service logic. The latter implies that the company orients all its processes to make the customer happy (e.g., to understand their needs, to create value for the customer), whereas the first implies that the company co-creates the service logic with the client (e.g., clients co-create value for themselves with the help of the company support). In order for this to happen, it is important that the company hires marketing managers that know how to develop a consumer behavior market analysis that aims at gauging sensory, emotional, communication behavior of the customer, rather than only cognitive behaviors. Basically, the variable to analyze is no longer solely the customer (his/her purchase behavior, needs, cognitive perceptions) but the interactions of the customer (his/her communication ecosystem, the quality of his/her relationships-communications, etc.). This implies shifting the focus from how customers think to how customers get in contact with others with a human touch (i.e., a human touch they expect also for themselves).

\subsection{Best (and Worst) Practices on Consumer Centricity (Topic 1)}

Articles that debate how employees' centricity is best implemented have identified a number of best practices in the field to be studied. A number of articles [47,48] have analyzed how Best Buy (Richfield, MN, USA) (electronic retail in the US) has launched a pilot test program of customer centric stores and has been successful in increasing sales and revenues. a.a.v.v [49] instead studied how the security system provider ADT LLC developed a coaching system (with the CEO being very active in it) that allowed the company to establish a customer-friendly environment, and to support customer centricity. Wolff [50] investigated Edison Electric Institute (EEI) member companies, which are transforming the energy grid and are creating customer-centric offers to their clients. a.a.v.v [51] investigates the case of the business-to-business service provider Rocketrip, which has established a partnership with Virgin America Airline in order to forge an employee centric model and a consumer-centric strategy. MacGillavry and Sinyan's article [52] focuses on DHL Freight collaboration with Gallup Inc. in order to initiate a cultural change from top-down management in order to bolster employee engagement and customer centricity. Moorthi [53] focuses on how IT Indian services companies (SWITCH—such as Satyam (Hyderabad, India), Wipro (Bangalore, India), Infosys (Bangalore, India), TCS (Mumbai, India), Cognizant (Teaneck, NJ, USA)) have initiated a number of "two-in-a-box" operating models that emphasize working together with the clients to make their business stronger (what has contributed to the growth of these companies). Besides these best practices, we also identified a number of articles [54] that highlight how some industries are particularly weak on customer centricity: these include banking, nonprofit, and insurance. Other articles instead focused on companies that are known as good for their customer centricity—such as the Cisco system [55] — but that had to re-organize their processes due to a market downturn, and therefore had to face the reality of putting their customer-centric programs and procedures at risk.

\subsection{Social Aspects of Consumer Centricity (Topic 3)}

Studies that drive the debate on social aspects of customer centricity are those that focus on the application of customer centric culture to improve the lives of customers or citizens. They, therefore, address the importance of having a strong leadership and organizational culture in the context of customer centricity for forging a socially responsible culture within the company to create value for society. For example, Pop et al. [56] debate how an increased customer orientation of pharmaceutical companies can improve patient well-being and align themselves to other organizations in the healthcare system. Rayburn and Marlys [11] focus on how social services are vital, and how customer centricity models may help to improve social services for what concerns housing, food, and medical assistance of individuals with economic issues. Additionally, other studies analyze how a patient-centric service delivery approach — that is based on principles of customer 
centricity - may improve patient lives within the hospital and at home $[57,58]$. Further studies [59] instead consider the process of internationalization of companies and discuss, for example, how policymakers in emerging countries may profit from putting in place a number of customer-centric oriented infrastructures that create the conditions for the survival and growth of international new ventures (INVs) in that country (which provide jobs and foster local economy).

\subsection{The Four Topics Across-Disciplines and Cross-Areas}

The heat map (see Figure 2) indicates which topic is particularly related to which discipline and area. Similarly, the correspondence matrix (see Figure 3) plots each one of the above-mentioned topics by considering which discipline (i.e., management vs. psychology) and area (i.e., leadership, organizational culture, co-creation) are initiating the debate in each one of them.

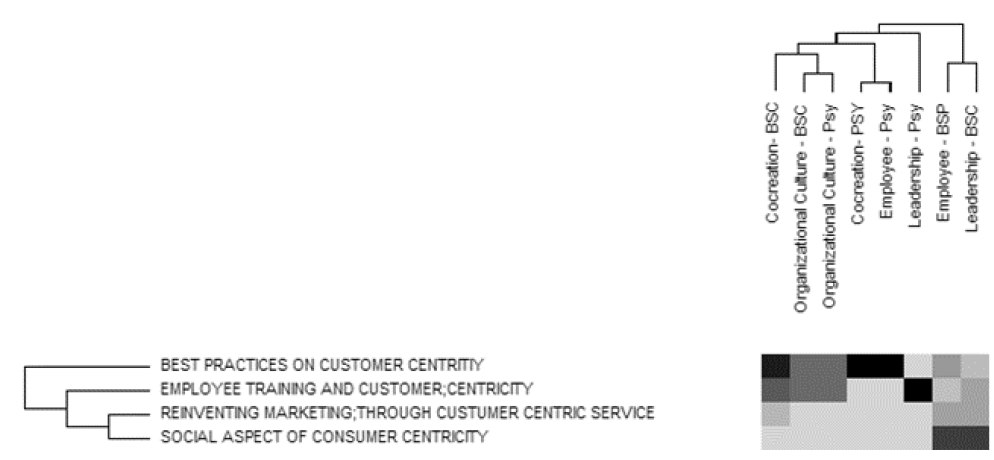

Figure 2. Heat map of cross-disciplines and cross-areas topics. Grey indicates very high intensity of this debate in that discipline area, black indicates very low to no intensity at all.

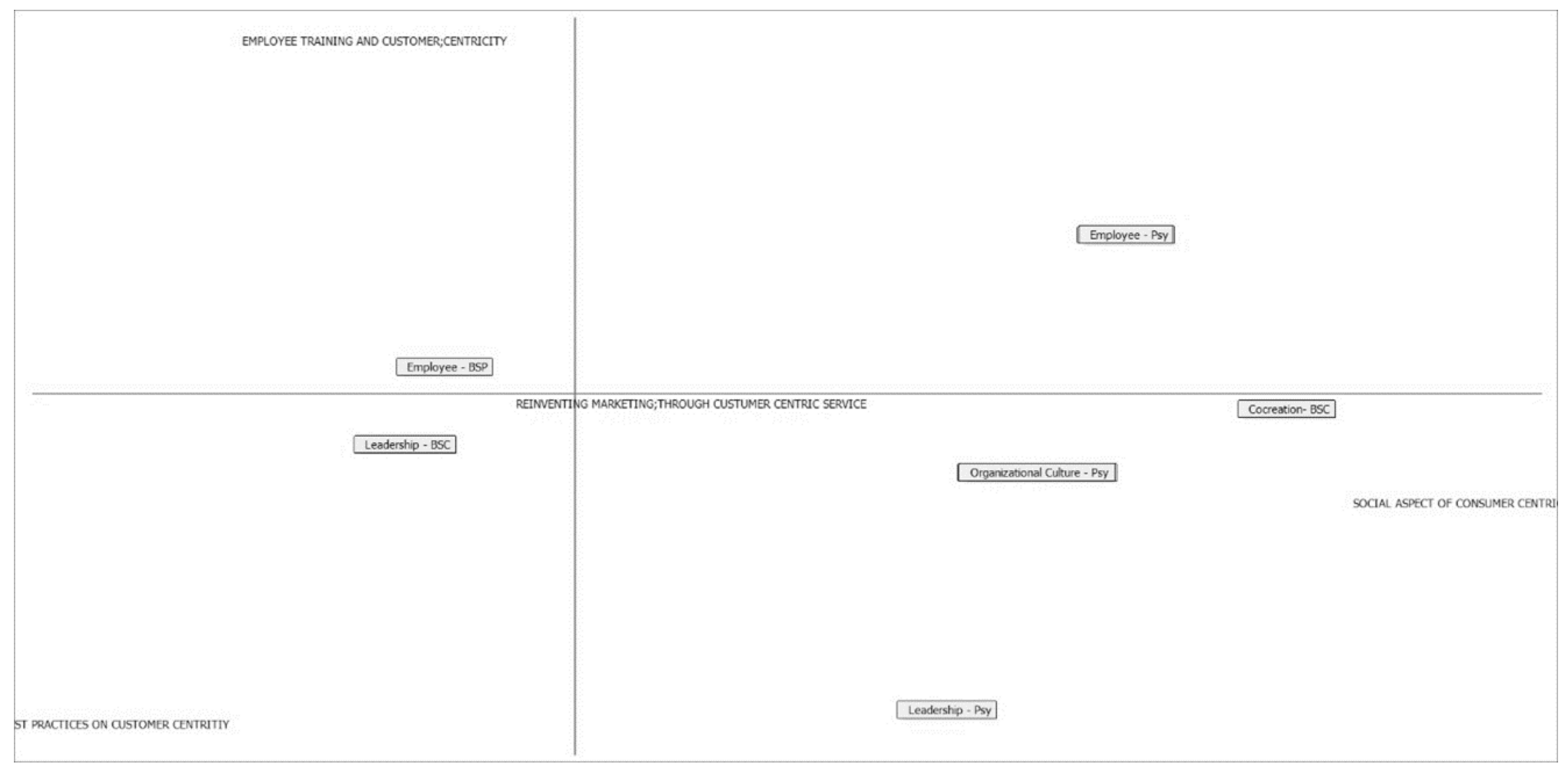

Figure 3. Correspondence matrix of topics extracted cross disciplines and areas.

From both figures, we can conclude that studies in management on employee and leadership are focusing on similar aspects of customer centricity, however, the latter tend to develop a higher number of considerations on best practices. Furthermore, we can highlight that studies in management that focus on co-creation are those that develop studies on social aspects of customer centricity the most, followed by studies on leadership, and organizational culture developed by psychologists. Finally, studies in psychology that focus on leadership, organizational culture, employees, and co-creation are those 
that mostly concentrate on the debate on reinventing marketing, followed by studies in management that develop research in employee engagement and leadership.

In light of all these considerations, we can draw the conclusion that studies in psychology are very consistent and tend to focus on two of the four debates: reinventing marketing and social aspects of customer centricity. However, studies in managementbusiness are highly active in the four debates with a particular focus on employee training and best practices.

\section{Conclusions}

A review of how management and psychology scholars employ the term customer centricity in an organizational context suggests that, while the field of customer centricity may seem fragmented, it is, in fact, a more coherent field than it first appears. This statement is supported by findings of our topic modeling analysis, which have identified four main topics that are recurrent across studies in management and psychology in the areas of organizational culture, employee engagement, and co-creation. These are: Employee training for the establishment of customer centricity; Best (and worst) practices on consumer centricity; Reinvention of marketing practices through customer centric service; Social aspects of consumer centricity. Furthermore, our review also suggests that, while studies have this common ground, there are differences in the way they approach the issue of how to establish a culture of customer centricity within organizations. While studies in management develop studies on the four topics and debates, studies in psychology focus their attention only on two of them, that is, reinvention of marketing practices through customer centric service and social aspects of consumer centricity.

The deep exploration of each one of the four identified topics allowed us to make the following considerations about a future research agenda on customer centricity, as well as do a reflection of how this figure agenda may allow for the advancement studies on relationship marketing. First, in order to forge further studies on consumer centricity, future research may best focus on how to establish a "balanced centricity", that is, a system of putting at the center not only the customer or the employee but all the involved agents. In addition, future research would benefit from considering how to build a system of sharing information and knowledge in the company that empowers employees by 1) allowing employees to access data with regards to customer satisfaction surveys, and 2) propose solutions with regards to weaknesses highlighted in these satisfaction surveys. Finally, future studies may also focus on how to put performance metric systems in place that allow us to understand how employees, with their daily work of building relationships with customers (and other agents involved in the process with the customer), are performing and contributing to corporate revenues. This allows to better fix training objectives for the future and thereby allows to support the shift from good-dominant logic to a servicedominant logic [28-30,42]. This allows as well to create a corporate culture, leadership, and identity that facilitates put customer retention as a high priority that transcends through all departments of an organization [7]. Second, in order to expand our understanding of how to reinvent marketing management, future research may develop studies on how to transform a system that enables companies to identify customer needs in order to serve them, into a system that enables customers to identify their needs and serve themselves. Additionally, future studies could analyze how to shift from a service logic to a servicedominant logic. The first implies that the company orients all its processes to make the customer happy (e.g., to understand their needs, to create value for the customer), whereas the second implies that the company co-creates the service logic with the client (e.g., clients co-create value for themselves with the help of the company's support). The focus on co-creation contributes in particular to studies of relationship marketing in that it allows to understand how to adopt a customer-centric vision $[4,5,22,25]$ which recognizes that customers are different and, thereby, the best way to target and maintain a long relationship with them is to support customers in serving themselves the product they want when they want. Third, in order to leverage on current best practices and improve worst practices in 
consumer centricity, future studies may develop additional best practices-oriented papers where customer centricity has been inserted with success: retail, IT, security industries. Moreover, scholars may want to analyze companies within industries where customer centricity still needs to be established: banking, nonprofit, insurance. This provides a contribution for relationship marketing studies as it may allow for boosting on the one hand studies on the best practices in retail, IT, and security industries, and on the other a good understanding of change processes that are necessary to insert a customer centric culture in banking, non-profit and insurance. Fourth, in order to explore how the customer centricity concept may become meaningful, scholars may develop further research on social aspects of consumer centricity by developing studies on how to forge a socially responsible culture within the company to create value for the society by creating customer centric programs that improve the well-being of individuals (customers). For example, scholarly works focused on health and pharmaceutical industries (e.g., patient-hospital relationship), social services (support for citizens with social issues), and governmental agencies (governmental-business relationship within emerging-developing countries). An exploration of this fourth research avenue would be particularly promising for studies on relationship marketing as, to our knowledge, scholars interested in analyzing CRM, customer loyalty, and satisfaction have mainly been interested in understanding how customer centricity stimulates profit and growth and competitive advantage [31-33,36], but have not focused on understanding the contribution of CRM systems and customer loyalty programs to create shared value [60], that is to increase business value but also social value. We consider that this would open new research avenues for studies on relationship management as they may end up contributing to the current debate on pillars of sustainability.

\section{Limitations}

The research method of topic modeling has several strengths: it is systematic and public; it can deal with a large amount of data; and, among other things, it offers a set of mature and well-documented procedures [61]. However, it tends to focus on frequencies and therefore may ignore the less common or non-existent ideas. Uncommon discussions using the term customer centricity were not considered. This is not a crucial limitation, given that in this manuscript our main aim is to identify the state of the art in the literature. Nonetheless, it is important to take it into consideration while making sense of the results. Additionally, our database and sample have been built with the assumption that abstracts collected from Business Source Premier are developed by management scholars, whereas abstracts collected from PsycInfo are by psychology scholars. This assumption may be criticized, as studies developed by management scholars adopting a psychological approach in their studies may be listed in PsycInfo, and vice versa. We considered, however, that the scholarly works, conference pieces, and articles within PsycInfo, are listed by undertaking the classification methods that are relevant for the American Psychological Association (APA), thus signaling their relevance for psychologists. Similarly, those listed in Business Source Premier are selected with the final aim to make available studies having a business relevance.

Author Contributions: Conceptualization, E.C. and L.I.; formal analysis, L.I.; investigation, F.B.; resources, E.C.; data curation, F.B.; writing-original draft preparation, E.C. and L.I.; writing-review and editing, M.B.; supervision, L.I. and M.B.; project administration, F.B. and M.B. All authors have read and agreed to the published version of the manuscript.

Funding: This research received external funding of the IE Centre for C-Centricity.

Institutional Review Board Statement: Not applicable.

Data Availability Statement: Not applicable.

Informed Consent Statement: Not applicable.

Conflicts of Interest: The authors declare no conflict of interest. 


\section{Appendix A}

Table A1. Outlets and databases where abstracts in our sample were published.

Both databases

European Journal of Marketing International Marketing Review

Journal of Service Research

\begin{tabular}{|c|c|}
\hline PsycInfo & $\begin{array}{l}\text { Asia Pacific Journal of Human Resources } \\
\text { Journal of Service Theory and Practice }\end{array}$ \\
\hline $\begin{array}{l}\text { Business Source } \\
\text { Premier }\end{array}$ & 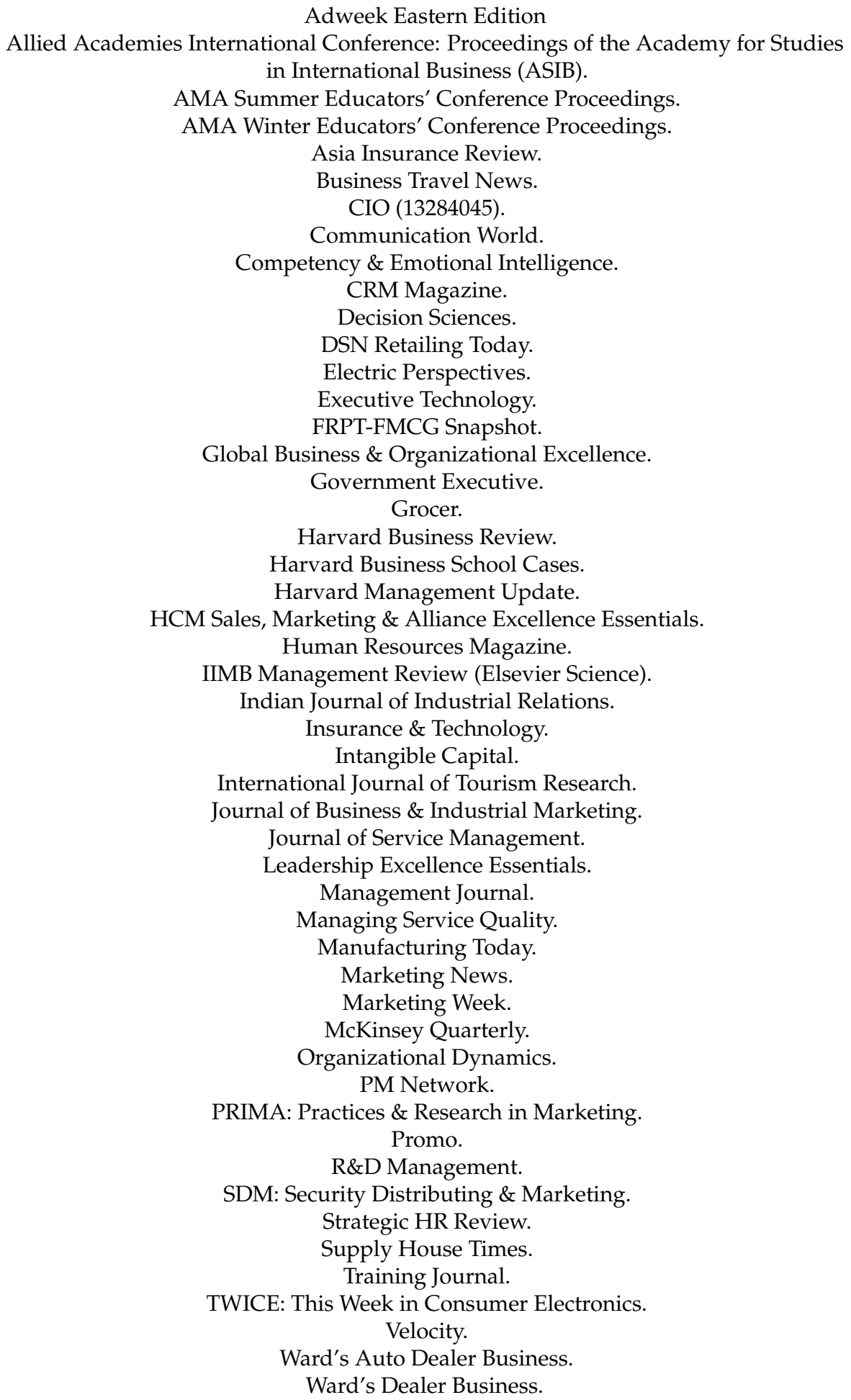 \\
\hline
\end{tabular}




\section{References}

1. Ascarza, E.; Ebbes, P.; Netzer, O.; Danielson, M. Beyond the Target Customer: Social Effects of Customer Relationship Management. J. Mark. Res. 2017, 54, 347-363. [CrossRef]

2. Gummerus, J.; vonKoskull, C.; Kowalkowski, C. Relationship marketing: Past, present, and future. J. Serv. Mark. 2017, 31, 1-5. [CrossRef]

3. Vargo, S.L. Towards a Transcending Conceptualization of a Relationship: A Service-Dominant Perspective. J. Bus. Ind. Mark. 2009, 26, 373-379. [CrossRef]

4. Fader, P. Customer Centricity: Focus on the Right Customers for Strategic Advantage, 2nd ed.; Wharton Digital Press: Philadelphia, PA, USA, 2012.

5. Lamberti, L. Customer centricity: The construct and the operational antecedents. J. Strateg. Mark. 2013, 21, 588-612. [CrossRef]

6. Shah, D.; Rust, R.T.; Parasuraman, A.; Staelin, R.; Day, G.S. The Path to Customer Centricity. J. Serv. Res. 2006, 9, 113-124. [CrossRef]

7. Gee, R.; Coates, G.; Nicholson, M. Understanding and profitably managing customer loyalty. Mark. Intell. Plan. 2008, 26, 359-374. [CrossRef]

8. Hart, C.W. Customers Are Your Business. Mark. Manag. 1999, 8, 6-7.

9. Kindström, D.; Kowalkowski, C.; Sandberg, E. Enabling service innovation: A dynamic capabilities approach. J. Bus. Res. 2013, 66, 1063-1073. [CrossRef]

10. Quero, M.J.; Ventura, R. The Role of Balanced Centricity in the Spanish Creative Industries Adopting a Crowd-Funding Organizational Model. J. Serv. Theory Pract. 2015, 25, 122-139. [CrossRef]

11. Rayburn, S.W.; Marlys, J.M. Service Outcomes-In: Social Services: An Application and Extension of Service-Dominant Logic. AMA Summer Educ. Conf. Proc. 2011, 22, 513-514.

12. Jo Hatch, M.; Schultz, M. Bringing the corporation into corporate branding. Eur. J. Mark. 2003, 37, 1041-1064. [CrossRef]

13. Chaussabel, D.; Sher, A. Mining Microarray Expression Data by Literature Profiling. Genome Biology. 2001, 3, 1-55.

14. Furrer, O.; Howard, T.; Goussevskaia, A. The Structure and Evolution of the Strategic Management Field: A Content Analysis of 26 Years of Strategic Management Research. Int. J. Manag. Rev. 2008, 10, 1-23. [CrossRef]

15. Illia, L. How Business Disciplines Discuss Multiple Identities in Organizations. Corp. Reput. Rev. 2010, 12, 327-344. [CrossRef]

16. Péladeau, N.; Davoodi, E. Comparison of Latent Dirichlet Modeling and Factor Analysis for Topic Extraction: A Lesson of History. In Proceedings of the 51st Hawaii International Conference on System Sciences, Waikoloa Village, Hawaii, USA, 2-6 January 2018; 2018; pp. 615-623.

17. Stephen, T. Computer-Assisted Concept Analysis of HCR's First 25 Years. Hum. Commun. Res. 1999, 25, 498-513. [CrossRef]

18. Ballantyne, D.; Christopher, M.; Payne, A. Relationship marketing: Looking back, looking forward. Marketing Theory. 2003, 3, 159-166. [CrossRef]

19. Mattsson, L.G. 'Relationship marketing' and the 'markets-as-networks approach' - A comparative analysis of two evolving streams of research. J. Mark. Manag. 1997, 13, 447-461. [CrossRef]

20. Berry, L.L. Relationship marketing of services: Growing interest, emerging perspectives. J. Acad. Mark. Sci. 1995, 23, 236-245. [CrossRef]

21. Sivadas, E.; Baker-Prewitt, J.L. An examination of the relationship between service quality, customer satisfaction, and store loyalty. Int. J. Retail Distrib. Manag. 2000, 28, 73-82.

22. Sheth, J.; Sisodia, R.S.; Sharma, A. The Antecedents and Consequences of Customer-Centric Marketing. J. Acad. Mark. Sci. 2000, 28, 55-66. [CrossRef]

23. Libai, B.; Bolton, R.; Bugel, M.; deRuyter, K.; Gotz, O.; Risselada, H.; Stephen, A. Customer to Customer Interactions: Broadening the Scope of Word of Mouth Research. J. Serv. Res. 2010, 13, 267-282. [CrossRef]

24. Hennig-Thurau, T.; Gwinner, K.P.; Gremler, D.D. Understanding Relationship Marketing Outcomes: An Integration of Relational Benefits and Relationship Quality. J. Serv. Res. 2002, 4, 230-247. [CrossRef]

25. Lapierre, J. Customer-perceived value in industrial contexts. J. Bus. Ind. Mark. 2000, 15, 122-140. [CrossRef]

26. Doney, P.M.; Cannon, J.P. An Examination of the Nature of Trust in Buyer-Seller Relationships. J. Mark. 1997, $61,35-55$.

27. Morgan, R.; Hunt, S. The Commitment-Trust Theory of Relationship Marketing. J. Mark. 1994, 58, 20-38. [CrossRef]

28. Gummesson, E. Relationship marketing as a paradigm shift: Some conclusions from the 30R approach. Manag. Decis. 1997, 35, 267-272. [CrossRef]

29. Grönroos, C. From marketing mix to relationship marketing: Towards a paradigm shift in marketing. Manag. Decis. 1994, 32, 4-20. [CrossRef]

30. Vargo, S.L.; Lusch, R.F. Evolving to a new dominant logic for marketing. J. Mark. 2004, 68, 1-17. [CrossRef]

31. Heskett, J.L. Beyond Customer Loyalty. Manag. Serv. Qual. 2002, 12, 355-357. [CrossRef]

32. Reichheld, F.F. Loyalty-Based Management. Harv. Bus. Rev. 1993, 71, 64-73.

33. Lam, S.Y.; Shankar, V.; Erramilli, M.K.; Murthy, B. Customer value, satisfaction, loyalty, and switching costs: An illustration from a business-to-business service context. J. Mark. Sci. 2004, 32, 293-311. [CrossRef]

34. Morgan, N.; Rego, L.L. The Value of Different Customer Satisfaction and Loyalty Metrics in Predicting Business Performance. Mark. Sci. 2006, 25, 426-439. [CrossRef] 
35. Shankar, V.; Smith, A.K.; Rangaswamy, A. Customer Satisfaction and Loyalty in Online and Offline Environments. Int. J. Res. Mark. 2003, 20, 153-175. [CrossRef]

36. Fornell, C.; Morgeson, F.V.; Hult, G.T.M. Stock returns on customer satisfaction do beat the market: Gauging the effect of a marketing intangible. J. Mark. 2016, 80, 92-107. [CrossRef]

37. Kumar, V.; Aksoy, L.; Donkers, B.; Venkatesan, R.; Wiesel, T.; Tillmans, S. Undervalued or Overvalued Customers: Capturing Total Customer Engagement Value. J. Serv. 2010, 13, 297-310. [CrossRef]

38. Brohman, M.K.; Piccoli, G.; Martin, P.; Zulkernine, F.; Parasuraman, A.; Watson, R.T. A design theory approach to building strategic net-based customer service systems. Decis. Sci. 2009, 40, 403-430. [CrossRef]

39. Seybold, P.B. The Customer Revolution: How to Thrive When Customers are in Control, 1st ed.; Crown Business: New York, NY, USA, 2001.

40. Grönroos, C.; Gummerus, J. The Service Revolution and Its Marketing Implications: Service Logic vs Service-Dominant Logic. Manag. Serv. Qual. 2014, 4, 206-229. [CrossRef]

41. Galbraith, J.R. Designing Organizations. An Executive Guide to Strategy, Structure, and Process; Jossey-Bass: San Francisco, CA, USA, 2002.

42. Gummesson, E. Extending the service-dominant logic: From customer centricity to balanced centricity. J. Acad. Mark. Sci. 2008, 36, 15-17. [CrossRef]

43. Stephen, T. Differentiating the U S. regional communication journals: A computer assisted concept analysis. In Proceedings of the Conference of International Communication Association, Washington, DC, USA, 24-28 May 2001.

44. Greenacre, M. Correspondence Analysis in Practice; Academic Press: London, UK, 1993.

45. Diday, E.; Pouget, J.; Lemaire, J.; Testu, F. Eléments d'Analyse des Données; Dounod: Paris, France, 1982.

46. Bailey, C. Examine Ways to Maximize Surveys. Mark. News 2002, 36, 46.

47. Johnson, L.K. How Best Buy's Executives Learn from the Front Lines. Harv. Manag. Update 2005, 10, 3-4.

48. Miller, L. Best Buy Gives a Face to Customer-Centricity. DSN Retail. Today 2004, 43, $23-27$.

49. Rocketrip CEO Dan Ruch Talks Traveler-Centric Future. Business Travel News. 2015. Available online: https://www. businesstravelnews.com/Business-Travel-Agencies/Rocketrip-Partners-With-Virgin-America-CEO-Dan-Ruch-Talks-TravelerCentric-Future (accessed on 30 April 2021).

50. Wolff, B. Creating a Customer-Centric Culture. Electr. Perspect. 2019, 44, 8.

51. A 'Three-Peat' Coach, ADT Named 2017 SDM Dealer of the Year. SDM Security Distributing and Marketing. 2017. Available online: https:/ / www.sdmmag.com/articles/94601-adt-named-2017-sdm-dealer-of-the-year (accessed on 30 April 2021).

52. MacGillavry, K.; Sinyan, P. Focusing on the Critical Link Between Employee Engagement and Customer Centricity at DHL Freight. Glob. Bus. Organ. Excell. 2016, 35, 6-16. [CrossRef]

53. Moorthi, Y.L.R. Non-Linear Growth: The Road Ahead for Indian IT Outsourcing Companies: The Cognizant Experience: In Conversation with R. Chandrasekaran, President and MD, Global Delivery, Cognizant. IIMB Manag. Rev. 2011, 23, 151-162. [CrossRef]

54. Awasthy, R.; Vijayalakshmi, C.; Gupta, R.K. Corporate Transformation or Cosmetic Makeover? Case of a Public Sector Bank in India. Indian J. Ind. Relat. 2013, 49, 67-81.

55. Gulati, R. Cisco Systems: Building and Sustaining a Customer-Centric Culture. Harvard Business School Cases. 2009 , pp. 1-21. Available online: https:/ / store.hbr.org/product/cisco-systems-2001-building-and-sustaining-a-customer-centric-culture/409061 (accessed on 30 April 2021).

56. Pop, O.M.; Leroi-Werelds, S.; Roijakkers, N.; Andreassen, T.W. Institutional Types and Institutional Change in Healthcare Ecosystems. J. Serv. Manag. 2018, 29, 593-614. [CrossRef]

57. Jayanti, R.; Subramaniam, K. A Patient Centered Service Delivery Mechanisms in an Emerging Economy: An Institutional Theory Perspective. MA Winter Educ. Conf. Proc. 2016, 27, 28-29.

58. Scheinbaum, A.C.; Wang, S.W. Customer Centricity and Guanxi Prevalence as Social Capital: A Study of International Business Relationships. J. Bus. Ind. Mark. 2018, 33, 1209-1220.

59. Kumar, N.; Sharma, D. The Role of Organisational Culture in the Internationalisation of New Ventures. Int. Mark. Rev. 2018, 35, 806-832. [CrossRef]

60. Kramer, M.; Porter, M. Creating shared value. Harv. Bus. Rev. 2011, 89, 62-77.

61. Bauer, M.; Gaskell, G. Qualitative Researching with Text, Image and Sound; Sage: London, UK, 2000. 